Caso para Ensino

\title{
Nosso Calendário Parou! A Mudança Organizacional na UFPB devido à COVID-19
}

\section{Our Calendar Stopped! The Organizational Change at UFPB due to COVID-19}

Disciplina: Comportamento Organizacional, Desenvolvimento Gerencial Temática: Mudança Organizacional, Tomada de Decisão

Setor de atividade: Educaçăo Superior, Universidade

Regiáo: Paraíba/Brasil
Diana Lucia Teixeira-de-Carvalho' ${ }^{10}$ Jose Jorge Lima Dias Junior ${ }^{10}$ Ana Carolina Kruta-Bispo ${ }^{10}$

\section{INTRODUÇÃO}

Era fim de tarde, e quem estava na Universidade Federal da Paraíba (UFPB) naquele dia já percebia que o fluxo de pessoas circulando havia diminuído. Acabara de ser comunicada a suspensão das atividades presenciais do período letivo 2019/2, que encerraria no dia 1 de abril. Mas ainda era março. Mais precisamente, 16 de março de 2020. A recomendação de distanciamento social por causa da pandemia da COVID-19 havia chegado à Paraíba, e a primeira decisão ponderada da reitora, Margareth Diniz, foi acatá-la, embora tenha impactado sobretudo no andamento das aulas de graduação.

Passada uma semana, a pró-reitora de graduaçáo (PRG), Ariane Sá, estava preocupada. A UFPB, pela sua

1. Universidade Federal da Paraiba, Centro de Ciências Sociais Aplicadas, Departamento de Administração, João Pessoa, PB, Brasil.

Como citar: Teixeira-de-Carvalho, D. L., Dias, J. J. L. Junior, \& Kruta-Bispo, A. C. (2021). Nosso calendário parou! A mudança organizacional na UFPB devido à COVID-19. Revista de Administração Contemporânea, 25(spe), e200249. https://doi.org/10.1590/1982-7849rac2021 200249.por dimensão e pela quantidade de pessoas circulando, poderia ter suas atividades presenciais suspensas por mais tempo. A previsão de apenas 15 dias de distanciamento social por causa do alto contágio da doença poderia não se aplicar para a realidade de uma organização como a UFPB. Portanto, era preciso realmente pensar à frente. Com isso em mente, convocou uma reunião remota urgente com sua equipe. "Pessoal, precisamos de um plano de ação para usarmos caso a suspensão das atividades presenciais da UFPB se estenda por tempo indeterminado. Andei conversando com a reitora e pensamos em propor um calendário especial, mas não sei como seria. Precisamos amadurecer essa ideia.”

Classificaçāo JEL: A20, H12, D91 Editor-chefe: Wesley Mendes-Da-Silva (Fundação Getulio Vargas, EAESP, Brasil) @] Editora Associada: Paula C. P. de S. Chimenti (Universidade Federal do Rio de Janeiro, COPPEAD, Brasil) (c) Editor Convidado: Leonardo Marques (Universidade Federal do Rio de Janeiro, COPPEAD, Brasil) (c) Pareceristas: Ana Luiza Szuchmacher V. Lopes (Universidade Federal do Estado do Rio de Janeiro, Brasil) (b) Um dos individuos revisores não autorizou a divulgação de sua identidade.

Relatório de Revisão por Pares: A disponibilização do Relatório de Revisão por Pares não foi autorizada pelos revisores. Recebido: $13 / 07 / 2020$ Última versão recebida em: 11/12/2020 Aceite em: 16/12/2020

\begin{tabular}{|c|c|c|c|c|c|c|c|c|c|}
\hline & 1 & 2 & 3 & 4 & 5 & 6 & 7 & 8 & 9 \\
\hline $1^{a}$ rodada & & & & & & & & & \\
\hline $2^{a}$ rodada & & & & & & & & & \\
\hline $3^{a}$ rodada & 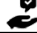 & & & & & & & & \\
\hline
\end{tabular}


A equipe sabia que não seria fácil, pois já estavam sendo identificados inúmeros problemas na condução do restante do período letivo, que nesse momento precisava terminar de forma remota. Muitos professores náo sabiam usar o módulo de Turma Virtual da plataforma Sigaa (Sistema Integrado de Gestão de Atividades Acadêmicas), o que dificultava a realização das atividades; outros ainda precisavam aplicar provas da última unidade do período letivo ou mesmo provas finais.

Isso sem falar nos estudantes. Não havia certeza de que todos estavam em condiçóes de terminar o semestre de forma remota, que dirá iniciar um calendário especial. Além disso, a complexidade dos processos da UFPB era algo que não poderia ser ignorado. Mesmo assim, todos concordaram que não deveriam simplesmente deixar o tempo passar, e se engajaram em elaborar uma proposta inédita e audaciosa.

Muitas reunióes sucederam nos 45 dias posteriores à conversa entre Ariane e sua equipe. Aparentemente, as resistências iniciais, que naturalmente acompanham a proposta de algo que nunca foi feito, começaram a diminuir, e as reuniôes com o fórum de assessores de graduaçáo de todos os centros da UFPB se tornaram mais produtivas.

Uma das questóes que mais preocupavam era o que ofertar em termos de calendário. Seria um período regular? Seria obrigatório para docentes e discentes? Deveria ter outro formato? Todas essas opçóes foram cogitadas, até que se definisse a possibilidade de se ofertar um calendário mais curto, metade do regular, sem obrigatoriedade para docentes e discentes.

E quanto às disciplinas? Seriam componentes curriculares ou cursos livres? Até que, em um esforço conjunto, que agregava bastante informação de todos os cursos, por meio dos assessores dos centros e de pesquisa conduzida pelo Observatório de Dados da Graduação (ODG), setor de assessoria da PRG, Ariane decidiu propor o que passou a ser chamado de Calendário Suplementar.

Um caminho rápido, porém cansativo, havia sido percorrido até o momento, mas ainda havia muito a ser feito. Diversos outros desafios precisavam ser superados, e o principal era como fazer essa proposta funcionar.

\section{A UFPB, A PRG E O ODG}

A UFPB, instituição autárquica de regime de ensino, pesquisa e extensão, vinculada ao Ministério da Educaçáo (MEC), desenvolveu uma estrutura multicampi, com atividades disseminadas em quatro campi instalados nas cidades de João Pessoa, Areia, Bananeiras e Litoral Norte (Rio Tinto e Mamanguape), organizados em 16 centros que comportam 120 cursos de graduação, 80 programas de pósgraduação, 2.700 docentes, 37.000 discentes e 3.522 técnicos- administrativos. Para entregar os serviços de ensino, pesquisa e extensão à sociedade, a UFPB tem a sua gestão formada pela reitoria, por oito pró-reitorias e pelas superintendências de tecnologia da informação (STI) e de ensino a distância (Sead), cada uma composta por suas respectivas equipes.

Além disso, por se tratar de uma instituição pública, as decisóes da UFPB são sempre colegiadas. Existem três órgãos deliberativos, que são o Conselho Superior de Ensino, Pesquisa e Extensão (Consepe), que delibera as matérias de natureza acadêmica; o Conselho Universitário (Consuni), órgão deliberativo superior em matéria de política geral da universidade; e o Conselho Curador, órgáo fiscal e deliberativo em assuntos econômicos e financeiros da universidade.

Especificamente sobre as atividades de ensino para a graduação, o Gabinete da Pró-Reitoria de Graduação (PRG) tem a missáo de "propor, coordenar e executar políticas acadêmicas e supervisionar as atividades de ensino dos cursos de graduaçáa”, sendo a Pró-Reitora dessa gestão a Professora Ariane Sá. Uma das açôes implementadas por Ariane foi a criação da assessoria que deu origem ao Observatório de Dados da Graduação (ODG), com o intuito de coletar, selecionar e difundir dados evolutivos sobre a situação dos cursos de graduação, coordenado pelo Professor Jorge Dias. Desde 2018, o setor atua no desenvolvimento de indicadores e aplicaçóes analíticas para auxiliar a PRG a tomar decisóes fundamentadas em dados. Isso se estendeu para o cenário pandêmico enfrentado pela UFPB naquele momento.

\section{A COVID-19 E O CALENDÁRIO SUPLEMENTAR}

Quando os impactos da pandemia causada pela COVID-19 atingiram a UFPB, a graduação terminava o calendário 2019/2. Em 2020 estava prevista a regularização dos períodos letivos, de modo que o período 2020/1 seria de abril a agosto, e o 2020/2 de agosto a dezembro. Desde 2017, professores e alunos, coordenaçóes e departamentos trabalhavam durante três períodos por ano para que, no espaço de três anos, o calendário da graduação pudesse ser normalizado, em decorrência da greve ocorrida em 2015.

No entanto, esse planejamento não deveria se manter. Uma vez que circulam diariamente na UFPB, em todos os seus campi, cerca de 40.000 pessoas por dia, a instituição passou a ser um local de alto risco de contaminaçáo da COVID-19. Somava-se a isso a preocupação com o fato de que muitas dessas pessoas pertenciam ao classificado grupo de risco e estariam mais vulneráveis, o que era difícil mapear imediatamente. Assim, por mais que fossem formuladas estratégias para diminuir a aproximação entre alunos e professores, como escalonamento, por exemplo, o isolamento social era indispensável naquele momento. 
O período 2019/2 deveria terminar remotamente, e isso ficou definido com base na expectativa de que o isolamento social poderia durar pelo menos dois meses, de modo que interromper o calendário por esse tempo representaria também perda para a comunidade acadêmica, que já estava com o calendário de aulas em relativo atraso. Todavia, essa decisão revelou um panorama preocupante em termos de execução, pois havia um grande número de professores que não tinha intimidade com o módulo da Turma Virtual do Sigaa, e que estava sem conseguir realizar atividades a distância, como as provas da última unidade do semestre ou as finais.

O período final do calendário $2019 / 2$ da graduação foi prorrogado para o dia 18 de abril, com o intuito de evitar maiores prejuízos na atuaçáo dos docentes causados por essa transição do presencial para o remoto. Quanto aos alunos, casos excepcionais deveriam ser analisados e resolvidos, para que todos pudessem terminar o período letivo de forma remota.

As atividades da pós-graduação, que nos primeiros dias de março iniciou o calendário 2020/1, assim como as atividades de pesquisa e de extensão, não pararam, aderindo às ferramentas on-line. Com isso, as pró-reitorias de pósgraduação (PRPG), de pesquisa (Propesq) e de extensão e assuntos comunitários (Prac) estavam atuando com certa normalidade, monitorando possíveis dificuldades e necessidades de adaptação.

A PRPG, inclusive, solicitou que a Pró-Reitoria de Gestâo de Pessoas (Progep) oferecesse capacitaçóes para os docentes dos programas de pós-graduaçáo a fim de minimizar as dificuldades de manuseio das plataformas digitais da UFPB na continuação remota do semestre 2020/1. Além disso, os coordenadores dos 10 cursos a distância da UFPB, juntamente com a Sead, decidiram manter suas atividades.
A situação dos cursos de graduação presencial era diferente, e a PRG enfrentava um cenário de incerteza. Afinal, com o término do calendário 2019/2, deveriam ser suspensas as aulas da graduação enquanto durasse o decreto de isolamento social? Com o pensamento de que era oportuno planejar alternativas, ainda em março Ariane reuniu os coordenadores da sua equipe, convocando-os para discutirem em conjunto.

Era um grande problema, principalmente porque, até então, apenas a Universidade Federal de Lavras (UFLA) mantinha suas aulas de graduaçáo de forma remota. Todas as demais universidades federais haviam suspendido o período letivo, diante de um contexto que ainda náo apresentava uma regulaçáo do próprio governo federal acerca de como as atividades deveriam funcionar.

A equipe da PRG vinha fazendo uma análise diária de tudo que estava sendo publicado, como portarias do MEC e minutas do Conselho Nacional de Educação, para entender as diretrizes nacionais para as universidades, mas não havia nada concreto. De fato, praticamente todos os gestores das universidades federais ficaram sem saber como agir, inclusive porque existem questóes legais relacionadas às diretrizes vigentes do MEC e da LDB (Lei de Diretrizes e Bases da Educação Nacional) sobre ofertar disciplinas a distância e isso por si só já limitava uma atuação diferente da prevista.

O governo federal disponibilizou, pelo site do MEC, painéis analíticos para que a sociedade acompanhasse quais instituiçôes federais de ensino estavam com suas atividades suspensas. O painel geral (Figura 1) apresentava os números de toda a Rede Federal de Ensino, composta por universidades e institutos federais, Cefets e Colégio Pedro II, sinalizando quantas ainda estavam com atividades suspensas.

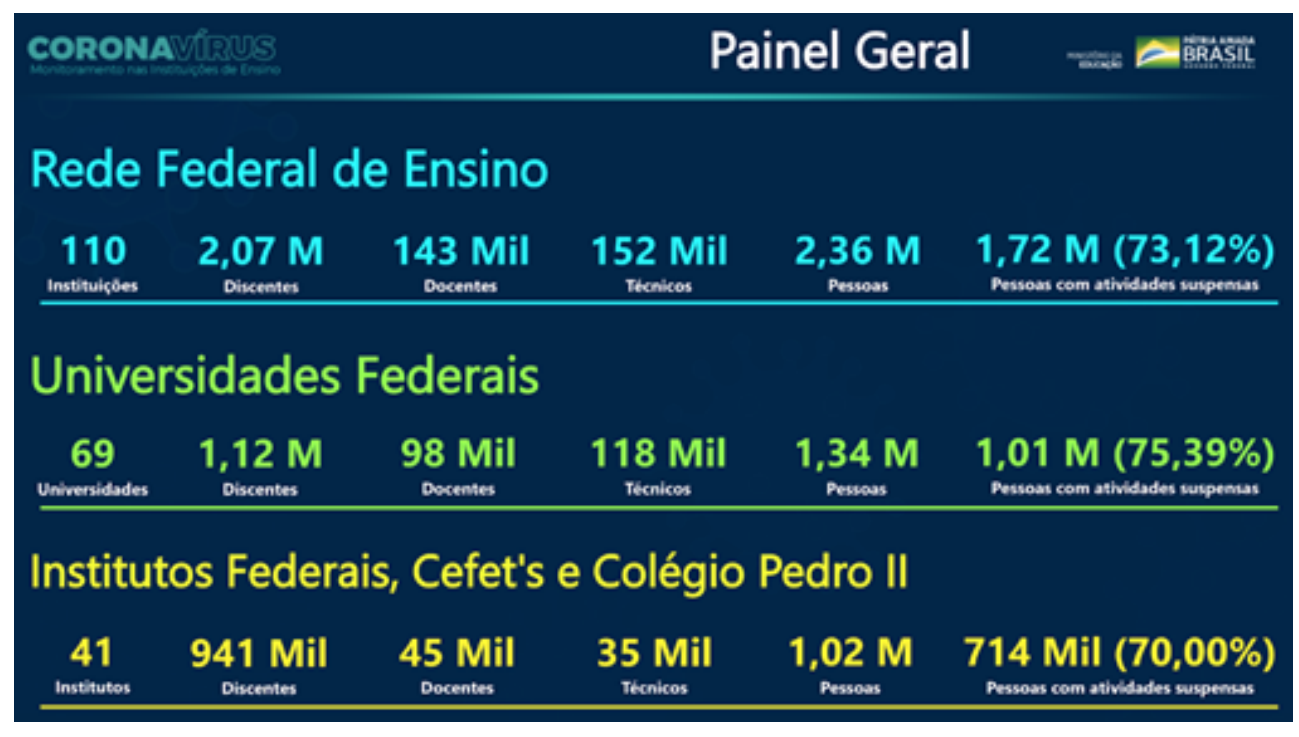

Figura 1. Painel geral de monitoramento da Rede Federal de Ensino.

Fonte: Brasil (2020). Ministério da Educação. Coronavírus: Monitoramento nas Instituiçōes de Ensino. Retrieved from http://portal.mec.gov.br/coronavirus/ 
Particularmente, o ministro da Educaçáo, no dia 20 de abril, publicou na sua conta pessoal do Twitter uma postagem (Figura 2) e divulgou, também nas redes sociais, um vídeo com uma mensagem que dizia respeito à mesma imagem de tal postagem: "Aqui na parte em azul são as universidades que já estão funcionando plenamente. Já retomaram suas atividades de forma remota ou presencial. Em amarelo retomou parcialmente a parte dos cursos, em vermelho a gente vai ter que correr atrás para ver o porquê que os alunos de graduação não voltaram. Vão acompanhando, vocês vão ver que isso daqui vai ficar tudo verde e amarelo. Vai sumir esse vermelho aqui em mais uma ou duas semanas."

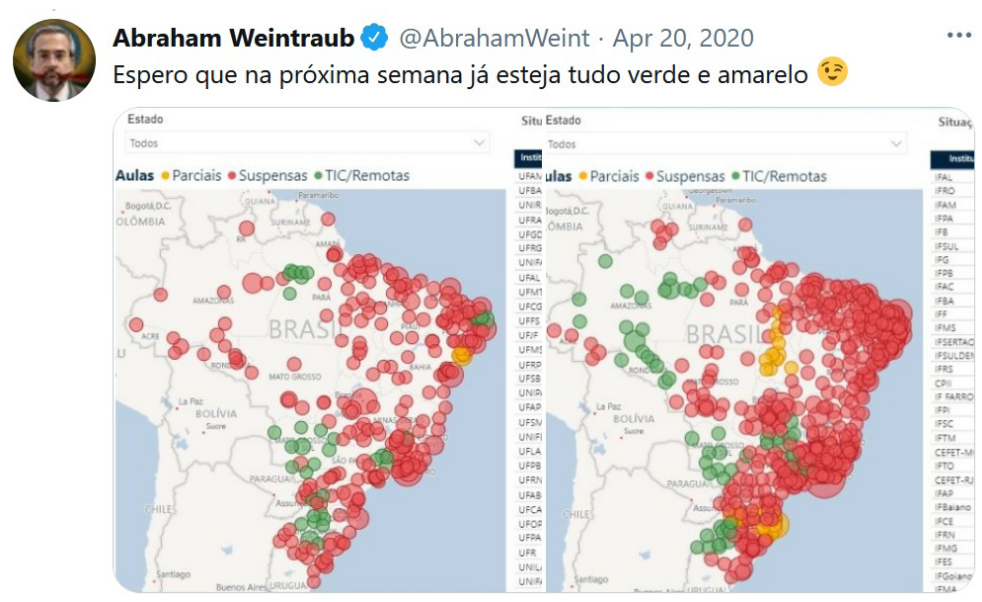

Figura 2. Tweet do ministro da Educaçáo e da Cidadania.

Fonte: Twitter.

Esse era o cenário externo que as IESs públicas estavam vivenciando. Independentemente disso, Ariane mantinha a ideia de que a UFPB poderia ser uma das vanguardistas em apresentar uma resposta para essa situação inesperada, mesmo estando ciente das dificuldades. Se a conclusão do período 2019/2, embora com tantos entraves narrados e enfrentados por professores e alunos, estava acontecendo, como não pensar em alternativas para pelo menos começar o semestre 2020/1?

Nesse momento, já passara um mês do início do isolamento social, e agora não havia previsão de retorno presencial. Era imprescindível considerar a viabilização de um modelo que possibilitasse aos professores se sentirem seguros para manejar. Uma grande preocupação, desde o começo, recaía na reação dos professores que precisariam aprender a atuar de maneira remota, mas Ariane confiava que o corpo docente da UFPB estaria disposto a enfrentar o desafio.

Diante desse cenário, Ariane entendeu que o grupo com o qual a PRG deveria iniciar as conversaçôes e ampliar o conhecimento sobre as possibilidades de execução desse calendário remoto era o fórum composto pelos 16 assessores de graduaçáo dos centros da UFPB, com os quais sua equipe se reunia todas as segundas-feiras, desde 2013. Nessas discussóes era possível compreender gradativamente como se posicionava cada centro, como poderia haver a aceitação de um calendário com um modelo alternativo nunca feito antes na UFPB, e quais açóes poderiam ser empreendidas, dadas as idiossincrasias de cada curso.

\section{PRIMEIRAS QUESTÕES E A NECESSIDADE DE UM DIAGNÓSTICO}

Inicialmente, houve uma resistência recorrente quando se falava em qualquer tipo de calendário para a graduação com aulas a distância. Os cursos iriam se transformar em $\mathrm{EaD}$ ? Argumentos logo surgiram sobre essa não ser a proposta da UFPB, ressaltando que o ensino presencial não poderia ser substituído, apenas complementado com atividades a distância. Os assessores de graduação insistiam que a educação a distância para os cursos presenciais era algo que iria contra as resoluçóes e diretrizes do MEC.

Diante dessa inquietaçáo, a equipe da PRG, após compreender que o termo "a distância" causara confusão durante a primeira reunião com os assessores de graduaçáo, pesquisou tipos de ensino com as características que estavam enfrentando e passou a utilizar o termo adequado. Naquele 20 de abril, era a segunda reuniáo que acontecia e, quando o burburinho reacendeu a discussão sobre $\mathrm{EaD}$, um dos coordenadores da PRG pediu a palavra, interrompendo-a: "Não se trata de EaD, pois essa possui uma estrutura já consolidada e organizada. Os professores que ensinam na 
EaD estão capacitados para preparar conteúdos e recursos pedagógicos nessa modalidade e contam com a atuação de tutores que auxiliam e lhes dão apoio no processo de ensinoaprendizagem. Além disso, há uma regulamentação própria, de maneira que não é porque estamos utilizando tecnologias a distância que estamos tratando de $\mathrm{EaD}$. O termo que a literatura vem utilizando é 'ensino remoto emergencial'. É remoto porque precisa ser aplicado de forma náo presencial, e é emergencial porque não houve planejamento para uma transição tão repentina. Esse termo não é novo. Países, por exemplo, que vivenciam guerra civil adotam esse modelo. A premissa é de que o ensino não deve parar e foi isso que fizemos para a continuação do calendário 2019/2" explicou ele.

A partir dessa reunião, ficou definido que a equipe da PRG passaria a utilizar o conceito de "ensino remoto emergencial" nos documentos e nas reunióes, evitando qualquer confusáo gerada pelo termo $\mathrm{EaD}$. Mas esse era apenas um dos questionamentos que Ariane e sua equipe ouviram durante as reunióes. Outro que causava certo alvoroço dizia respeito à possível inacessibilidade dos alunos à internet, posto que, em divulgação feita para a comunidade acadêmica por e-mail, um boletim informativo revelou que $42 \%$ dos alunos viviam em situaçáo de vulnerabilidade por ter renda familiar de até dois salários mínimos. A possibilidade de que um calendário ofertado durante o período de isolamento social pudesse vir a gerar desigualdade foi um impasse que logo surgira: "Ariane, e os alunos em situação de vulnerabilidade social? Como serão incluídos?” - perguntou um dos assessores de graduação. "Sem falar nos alunos com necessidades especiais. Se, muitas vezes, já é difícil para eles acompanharem as aulas presenciais, como faremos se forem remotas?" - emendou outro.

Ao mesmo tempo, sem uma definição do que seria a proposta, havia uma polarização: por um lado, defendiase que se um único aluno não tivesse acesso a qualquer tipo de oferta, a UFPB estaria reforçando a desigualdade; por outro, a pressáo pela oferta de um calendário regular foi feita por alguns centros. Diante disso, após essa reuniáo, Jorge sugeriu: "Ariane, precisamos ter um diagnóstico sobre o perfil dos estudantes" - disse ele. - "O que sabemos sobre eles terem ou não capacidade de receberem aulas remotas? Nada! De repente, $42 \%$ dos alunos terem renda familiar de até dois salários mínimos virou não terem acesso à internet?! Independentemente do resultado, decisões, ações e estratégias precisam ser balizadas por dados." "Sim, Jorge! Acho fundamental" - Ariane concordou.

Com base nessa conversa, Jorge ficou responsável por realizar uma pesquisa que a PRG ofereceria como diagnóstico para esclarecer os possíveis impactos que um calendário de formato alternativo representaria para os estudantes. Para entregar à comunidade acadêmica uma pesquisa institucional que pudesse embasar a tomada de decisão, o ODG elaborou um questionário com o objetivo de diagnosticar o perfil de acesso à internet e às tecnologias remotas dos estudantes da UFPB.

Entretanto, esse foi outro processo que encontrou alguns desafios, pois, antes que o ODG pudesse aplicálo, várias outras entidades da instituição (coordenaçôes de curso, centros acadêmicos estudantis, o Diretório Central dos Estudantes, etc.) aplicaram questionários próprios e publicaram os respectivos resultados. Diante disso, muitas dessas entidades, além do resultado, deliberavam a decisão sobre serem a favor ou não de um período com atividades remotas.

Um desses relatórios foi publicado pelo Centro Acadêmico Estudantil de um dos cursos da UFPB. A pesquisa disponibilizada via formulário do Google Forms obteve 296 respostas, o que representou 64,35\% do total de estudantes desse curso. Ainda segundo o relatório, 97,3\% dos estudantes residiam em área urbana. Daqueles que moravam em zona rural, $50 \%$ não possuíam computador e 12,5\% não tinham celular. Além disso, do total de estudantes que responderam ao questionário, $1,35 \%$ não possuíam acesso à internet.

Segundo o relatório, esse ponto evidenciaria a não efetiva capacidade de institucionalização das atividades remotas. Ao final, o relatório revelou seu posicionamento contrário à implementação de atividades remotas, uma vez que beneficiaria apenas uma parcela do curso. Esse foi apenas um dos diversos resultados obtidos por essas pesquisas paralelas à do ODG, e muitas expunham as posiçóes das entidades que as aplicaram no que dizia respeito a um período realizado remotamente.

Simultaneamente, o ODG preparava o instrumento para realizar a pesquisa institucional, com base em um cuidadoso conjunto de conceitos de mensuração, a fim de obter confiabilidade dos dados. Com essa preocupaçáo, Jorge convidou alguns professores com experiência em pesquisa quantitativa para validarem o questionário que deveria ser respondido pelos estudantes. Outra decisão foi operacionalizar as respostas por meio da plataforma oficial da UFPB, o Sigaa, o que garantiria a autenticidade - pois apenas alunos da UFPB responderiam - e unicidade das respostas, o que evitaria que um estudante registrasse mais de uma resposta.

Com o questionário pronto, ainda em abril os estudantes foram mobilizados a responderem via comunicação no Sigaa e por meio de diversas redes sociais vinculadas à UFPB. Todavia, o tempo era curto, pois muitas unidades institucionais aguardavam o resultado da pesquisa para se posicionarem, bem como era importante que esses 
dados pudessem balizar a tomada de decisão da PRG junto às demais entidades da universidade.

O período de aplicação da pesquisa foi, portanto, de apenas uma semana, e muitos alunos já tinham respondido aos questionários das outras entidades. Mesmo assim, mais de 14.000 estudantes da graduação os responderam, o que representou cerca de $60 \%$ dos estudantes que em média se matriculam em um período regular.
Diferentemente das pesquisas on-line realizadas pelas demais entidades da UFPB, o ODG operacionalizou o cruzamento de dados do questionário com dados socioeconômicos, para garantir a representatividade da amostra. Com isso, Jorge verificou que a maioria dos respondentes tinha origem de escolas públicas (Figura 3) e possuía até dois salários mínimos (Figura 4), o que estava de acordo com as características socioeconômicas do total de estudantes da instituição.

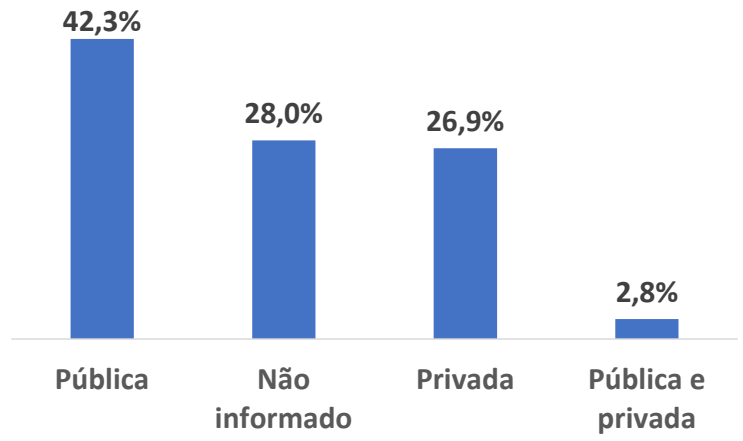

Figura 3. Escola de origem dos estudantes.

Fonte: Observatório de Dados da Graduaçấo. Dados da pesquisa do ODG. Retrieved from https://linktr.ee/odg_prg_ufpb

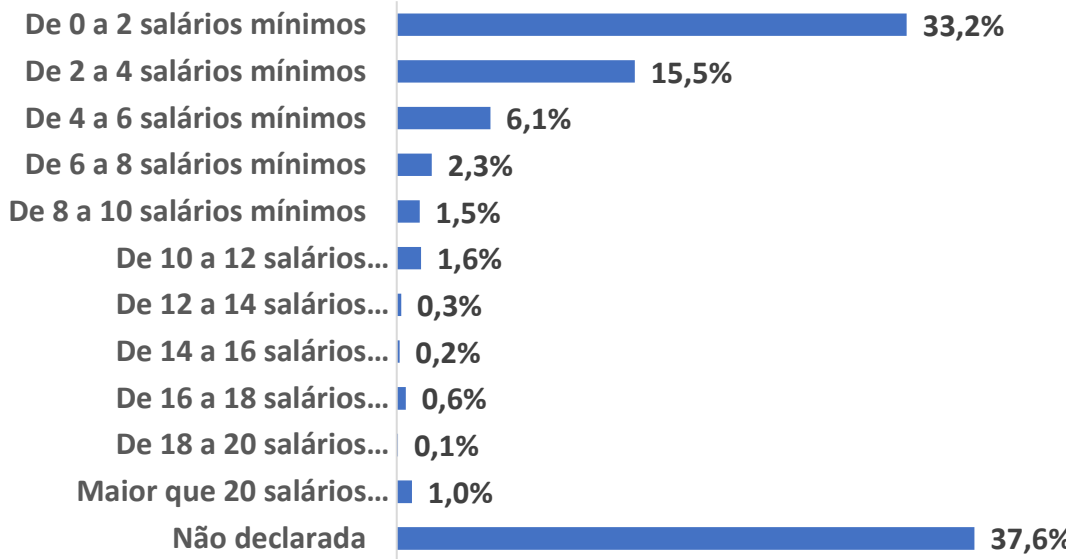

Figura 4. Renda familiar dos estudantes.

Fonte: Observatório de Dados da Graduaçấo. Dados da pesquisa do ODG. Retrieved from https://linktr.ee/odg prg ufpb

Ao analisar os dados, Jorge também identificou que $84 \%$ dos respondentes possuíam computador ou notebook para suas atividades acadêmicas (Figura 5), e que $90 \%$ tinham acesso à internet de banda larga. Esse percentual chegava a $99 \%$ quando se tratava de algum tipo de acesso, de modo que $98 \%$ acessava a internet todos ou quase todos os dias. Ademais, os dados revelaram que $91 \%$ dos respondentes tinham condiçóes adequadas para assistir a vídeos on-line e $91 \%$ para ler um texto em qualquer formato. 
Tenho computador em domicílio com condições de usar softwares/programas comuns

Tenho computador em domicílio mas ele possui restrições de velocidade e memória que prejudicam o uso regular de softwares comuns

Não tenho computador, nem tenho acesso de outras formas

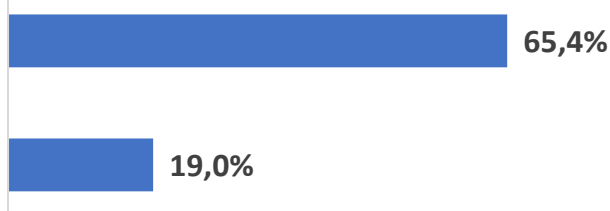

$8,3 \%$

Não tenho computador em domicílio mas consigo ter acesso a um de outras formas (amigos, família etc)

Figura 5. Perfil de acesso às TICs.

Fonte: Observatório de Dados da Graduaçáo. Dados da pesquisa do ODG. Retrieved from https://linktr.ee/odg_prg_ufpb

Além disso, a pesquisa revelou que $76 \%$ dos estudantes apontavam que provavelmente participariam de atividades remotas caso o seu curso as ofertasse durante o isolamento social. Contrariamente, um percentual de $14,4 \%$ respondeu que não teria interesse e $11,5 \%$ dos estudantes se mostraram indiferentes. Por fim, o ODG obteve a informação de que, dos estudantes com até dois salários mínimos e que vieram de escola pública, $80 \%$ tinham computador ou notebook; e $84 \%$ tinham acesso à internet de banda larga, sendo que $99 \%$ possuíam algum tipo de conectividade. Com isso, $68 \%$ dos estudantes com esse perfil afirmaram que participariam das atividades remotas durante o isolamento social, caso houvesse alguma.

A partir do início de maio, Jorge apresentou os dados em diversas reunióes, até chegar à do Consepe. Além disso, elaborou e disponibilizou painéis analíticos, o que permitiu à comunidade acadêmica explorar os dados por meio de diversos filtros. Os resultados, em boa medida, surpreenderam à comunidade, principalmente sobre o percentual de estudantes que possuem conectividade com a internet e acesso a computador. Mesmo assim, na reunião com o Consepe, um dos conselheiros indagou: " $\mathrm{E}$ os outros $40 \%$ ? Onde estão?” - essas eram perguntas que continuavam a repercutir.

\section{DIANTE DE NOVOS DESAFIOS, O QUE DECIDIR?}

Tinham-se passado quase dois meses. Era começo de maio e Ariane gostaria de iniciar o calendário suplementar no máximo em junho, afinal, alunos e professores estavam sem aula na graduaçáa desde meados de abril. Nesse momento, Ariane e sua equipe já participavam de reunióes com os conselhos de centro, além das regularmente realizadas com os assessores de graduação. Com isso, a PRG tinha esboçado a versão preliminar de uma minuta de resolução, mesmo sabendo que ainda poderia mudar muito quando fosse submetida ao Consepe e seus 44 conselheiros titulares.

Realmente, o grande desafio era haver um consenso na comunidade acadêmica sobre a proposta. Alguns departamentos e cursos estavam relutantes em aceitar a realização de um calendário suplementar. A essa altura, a equipe da PRG já tinha pensado no caráter facultativo que esse período deveria ter, tanto para professores quanto para alunos. Isso porque considerou a impossibilidade de exigir que todos os alunos estivessem aptos a cursar disciplinas remotamente, bem como a carga horária dos professores, que não poderia ultrapassar as 40 horas semanais, pois muitos não tinham parado as atividades, atuando na pesquisa e na extensão.

De todo modo, o formato estava definido. O calendário suplementar teria duração de 10 semanas e os cursos ofertados poderiam ser livres ou de componentes curriculares. Mas ainda havia muitas questóes que estavam gerando insegurança no corpo docente. Várias entidades e associaçóes de classe lançaram notas com posicionamento contrário a um possível calendário suplementar e, mesmo que esse contexto não fosse suficiente para desanimar a equipe da PRG, à medida que as reunióes foram avançando, novas possíveis problemáticas foram sendo elencadas: "Prezados, precisamos considerar que nossos professores sáo preparados para dar aulas presenciais e não para dar aulas remotas!" - reclamou Roberto, professor há 28 anos na instituição. "Além disso, elaborarmos materiais para aulas remotas, sem estarmos preparados, demandará muito mais horas de trabalho. Estou preocupada. Como ficará nossa carga horária semanal?" - questionou a professora Amália. "Outro problema que precisa ser considerado é que o módulo da Turma Virtual do Sigaa não tem os recursos necessários para darmos aulas remotas adequadamente! Eu mesma acredito que seja uma ferramenta apenas de suporte" - destacou a Professora Maria, que também atuava em um curso de EaD 
na instituição. "Gente, vocês estão considerando que muitos professores possuem filhos? Como terão condições de dar aulas com as crianças em casa?" - o professor Inácio lembrou.

Diante de tantos questionamentos, Ariane ponderou: "Eu entendo as questóes apresentadas, senhores e senhoras, mas precisamos fazer algo. É preciso lembrarmos que esse é um período de excepcionalidade, que o caos gera mudança, gera possibilidades, e isso é o que estamos tentando fazer aqui. A pesquisa e a extensão não pararam. Como ficará o ensino? Precisamos considerar a necessidade de dar uma resposta à sociedade, caso a suspensão das atividades presenciais seja estendida. Sei que é necessário termos mais informaçóes para avançarmos, e que nossas discussóes devem ser lapidadas, mas teremos todo o cuidado possível que a situação exige e sabemos que nossos professores são entusiasmados e engajados com a nossa comunidade" - disse ela, de maneira pragmática, o que acalmou os ânimos na reunião.

Todavia, Ariane não podia ignorar os obstáculos. Sabia que as preocupaçóes expressadas nas intermináveis reunióes precisavam ser resolvidas para que um calendário de ensino remoto emergencial pudesse funcionar. A grande maioria dos professores náo era capacitada para esse tipo de ensino e, por mais que a Progep tivesse oferecido alguns cursos de formação durante o término do calendário 2019/2, a evasão tinha sido de quase $90 \%$ dos docentes que se inscreveram. Em termos operacionais, como ficaria a atuação do professor com base no uso de ferramentas remotas, principalmente diante da pluralidade de habilidades, que ia desde uma recorrente utilizaçáo a uma completa falta de intimidade com esse tipo de ferramenta?

Houve ainda professores que creditaram a evasão dos cursos promovidos pela Progep à dificuldade com o manuseio do Moodle. O Sigaa, não tendo todas as funcionalidades necessárias para um ensino remoto, precisaria ser substituído por outra plataforma mais completa. Nesse sentido, começaram as capacitaçóes do Moodle, ambiente virtual de aprendizagem (AVA), utilizado pela $\mathrm{EaD}$, para todos os professores da pós-graduação, com várias turmas compostas por mais de 100 docentes para serem capacitados.
Porém, o sistema não era intuitivo e as tarefas eram difíceis de serem realizadas, o que fez com que os prazos para encerramento dos cursos fossem estendidos pelo menos duas vezes em um período de dois meses. Mesmo assim, o resultado foi a alta evasão. Isso sinalizava mais dois problemas difíceis de serem ignorados. A capacitação dos professores para ensinar remotamente precisava ser efetiva e a plataforma oficial para realização de um período suplementar deveria ser mais atrativa.

Diante desse contexto, como operacionalizar o período suplementar? A preocupação de Ariane sempre foi continuar prestando serviço para a sociedade. Mesmo ciente das dificuldades para uma instituição como a UFPB ser adaptada rapidamente a um cenário inesperado, ela tentava se manter confiante de que seria possível, de modo excepcional, voltar a ofertar aulas para os cursos de graduação.

No entanto, quanto mais avançavam, mais obstáculos surgiam. Ainda era preciso convencer a comunidade acadêmica sobre o significado de um calendário suplementar? Como preparar a tempo o corpo docente táo diverso da UFPB? E sobre a infraestrutura, as ferramentas atuais seriam adequadas para as necessidades do período remoto? $\mathrm{O}$ sistema de gestáo acadêmico estaria apto para dar suporte a um período especial? Como ficaria o processo das matrículas, por exemplo?

No fim de uma semana de muitas reunióes, nas quais tantas questóes foram apresentadas, a última foi com o grupo de pró-reitores de graduação das IESs públicas da Paraíba. Nela, os pró-reitores discutiam a possibilidade de um calendário de atividades remotas nessas instituiçóes, mas ainda de forma especulativa, quando na UFPB já se tinha avançado até a redação de uma minuta de resolução. Entretanto, isso fez Ariane refletir. Diante de todos esses outros desafios, seria melhor tentar prosseguir com a implementação do calendário suplementar na UFPB ou recuar e esperar que outras IESs públicas se mobilizassem para que a equipe da PRG pudesse se basear em algum modelo e facilitar esse processo? 
Notas de Ensino

\section{RESUMO}

Este caso para ensino tem o objetivo de analisar o contexto da Universidade Federal da Paraíba, que vivencia os impactos do isolamento social devido à COVID-19, sobretudo na realização das aulas de graduação, considerando que as atividades presenciais foram suspensas. $O$ caso apresenta os fatos relacionados à possibilidade de implementação de um calendário suplementar, com base no conceito de ensino remoto emergencial. Diante desse cenário, era necessário dos gestores da Pró-Reitoria de Graduação um planejamento cuidadoso para gerenciar as incertezas e as resistências às mudanças que tal proposta representaria, principalmente porque não havia modelos para se basearem, uma vez que praticamente todas as IESs públicas estavam com as aulas de graduaçáo suspensas. $\mathrm{O}$ caso levanta um dilema principal: Diante dos desafios para implementar um calendário suplementar remoto, é melhor seguir ou recuar? Os objetivos pedagógicos deste caso para ensino envolvem: analisar o impacto da COVID-19 no comportamento organizacional; discutir os aspectos relativos à implementação de mudanças organizacionais; identificar o uso de dados para a tomada de decisão e suporte para a mudança organizacional; e tomar decisóes frente a dilemas gerenciais. Sua análise pode ser feita por alunos da graduação, dos cursos de Administração e Gestão Pública.

Palavras-chave: IES; mudança organizacional; tomada de decisão fundamentada em dados; gestão acadêmica.

\section{OBJETIVOS EDUCACIONAIS E RECOMENDAÇÕES DE APLICAÇÃO}

O caso para ensino tem o objetivo de analisar o impacto da COVID-19 no comportamento organizacional, considerando que o cenário resultante da pandemia é composto por inúmeras incertezas e necessidade de adaptação de uma IES pública. Desse modo, é esperado que o caso proporcione aos alunos as seguintes competências: (a) compreender os aspectos relativos à implementação de mudanças organizacionais, tendo em vista a complexidade de uma IES pública; (b) reconhecer o uso de dados para a tomada de decisáo e como suporte para o planejamento da mudança organizacional; e (c) vivenciar a tomada de decisão organizacional diante de dilemas inerentes à atuaçáo do

\section{ABSTRACT}

This teaching case aims to analyze the context of the Federal University of Paraíba, which experiences the impacts of social isolation due to COVID-19, especially in conducting undergraduate classes, considering that the activities face-to-face were suspended. The case presents the facts related to the possibility of implementing a supplementary calendar, based on the concept of remote emergency teaching. Because of this scenario, the Pro-Rectory of Graduation managers needed to plan carefully to manage the uncertainties and resistance to changes that such a proposal would represent, mainly because there were no models to be based on since practically all public HEIs have suspended graduation classes. The case raises a significant dilemma: in the face of the challenges of implementing a supplementary remote calendar, is it better to follow or step back? The pedagogical objectives of this teaching case involve: analyzing the impact of COVID-19 on organizational behavior; discuss aspects related to the implementation of organizational changes; identify the use of data for decision-making and support for organizational change; and making decisions in the face of managerial dilemmas. Its analysis can be done by undergraduate students, in Administration and Public Management courses.

Keywords: HEI; organizational change; data-based decision-making; academic management. gestor de uma IES. O caso é recomendado para ser aplicado, prioritariamente, nas disciplinas de Comportamento Organizacional, Desenvolvimento Gerencial, Processo Decisório, Gestão de Pessoas e Gestão Educacional. Adicionalmente, embora a análise do caso não direcione para essas disciplinas, é possível que sejam identificados aspectos relacionados às disciplinas de Pesquisa de Mercado, Administração de Recursos Humanos e Gestão de Projetos, a depender do encaminhamento feito pelo professor. A indicação de análise do caso é feita preferencialmente para os cursos de graduação de Administração e Gestão Pública. 


\section{FONTES DE DADOS}

Os dados foram primordialmente obtidos de maneira primária a partir da realização de entrevistas semiestruturadas com os principais atores do caso, a pró-reitora de graduação da UFPB e o coordenador do Observatório dos Dados da Graduação. Além disso, dados oriundos de observação participante, a partir do acompanhamento de reunióes online dos conselhos e da participação em reuniôes de comissóes formadas para o enfrentamento da crise, a exemplo da comissão de capacitação docente e discente, foram utilizados na elaboraçáa deste caso. De maneira complementar, dados secundários obtidos em relatórios internos, nos sites da UFPB, da PRG (Universidade Federal da Paraíba, 2019; 2020) e do MEC (http://portal.mec.gov.br/coronavirus/ recuperado em 12 de Agosto, 2020), e nas redes sociais também foram usados. Os nomes de alguns personagens foram modificados, mas o nome da instituição e dos protagonistas, bem como os fatos apresentados, são todos reais.

\section{QUESTÕES PARA ANÁLISE}

Questáo 1. Em razão do isolamento social ocasionado pela pandemia da COVID-19, a UFPB propôs implementar um calendário suplementar para ser executado de maneira remota. Como você analisa o processo de mudança organizacional requerido nesse contexto enfrentado pela UFPB?

Questáo 2. Considere que toda mudança pressupóe resistência. No caso da implementação do calendário suplementar na UFPB, como você avalia as manifestaçóes de resistência da comunidade acadêmica e quais açôes foram ou poderiam ter sido realizadas para superá-las?

Questáo 3. Discuta o papel do Observatório de Dados da Graduação $(\mathrm{ODG})$ para a tomada de decisão no processo de mudança organizacional da UFPB.

Questáo 4. Ao se colocar na posição de Ariane, como próreitora de graduaçáo, qual seria a sua decisão, seguir ou recuar com o calendário suplementar? Apresente argumentos para justificar sua escolha.

\section{PROPOSTA DE PLANO DE AULA}

Antes do início da análise deste caso, indica-se que o professor ressalte a relevância da utilização de um caso para ensino para o aprendizado, explicando a relaçáo entre teoria e prática que essa estratégia implica. Adicionalmente, propóese que o professor solicite aos alunos que realizem uma breve pesquisa sobre o serviço de ensino superior público, para que se familiarizem com o contexto organizacional em tela, a fim de estimular o engajamento e o entendimento dos alunos sobre as temáticas relacionadas ao caso de modo geral. Ainda, é preciso que o professor disponibilize o caso e as questóes com antecedência mínima de uma semana, solicitando a leitura e a resposta individual das questóes.

Para a condução da sessão de análise do caso, propóem-se quatro etapas para uma aula com duraçáo de duas horas:

1. Abertura (tempo estimado: 10 minutos) - $\mathrm{O}$ professor pode iniciar a sessão com questóes mais gerais, que abordem as implicaçóes de fatores externos nas organizaçóes, como a pandemia da COVID-19, favorecendo um tipo de aquecimento à discussão. Com isso, podem ser feitas questôes como: De modo geral, quais implicaçóes são visualizadas no contexto interno das organizaçóes em decorrência da pandemia? Quais oportunidades e ameaças as organizaçóes enfrentaram? Ainda, o professor pode incentivar os alunos a revelarem aspectos importantes pesquisados sobre o contexto das IESs públicas.

2. Discussão em pequenos grupos (tempo estimado: 40 minutos) - O professor deve estimular que, em pequenos grupos de três a quatro pessoas, os alunos discutam as respostas das questóes descritas no caso, analisando e propondo soluçóes conjuntas. Para tanto, sugere-se que sejam separados grupos aleatórios, a fim de estimular o debate e desenvolver competências sociais e emocionais, além das competências técnicas.

3. Discussão no grande grupo (tempo estimado: 40 minutos) - Após discussão, indica-se que cada grupo apresente oralmente a sua análise e a solução do dilema enfrentado pela instituição, com o professor incitando o debate e incentivando a participação dos alunos. $\mathrm{O}$ professor deve ficar atento aos possíveis pontos conflitantes, para que possa fomentar a discussão construtiva sobre o tema.

4. Fechamento da discussão (tempo estimado: 30 minutos) - O professor deve realizar o fechamento da discussão, propondo direcionamentos para análise a partir das opiniōes manifestadas pelos alunos e discutindo as alternativas propostas, podendo utilizar o quadro para elencá-las, de modo que os resultados da discussão fiquem visíveis para todos.

Apesar da estimativa de tempo para cada etapa, entende-se que, a depender da heterogeneidade e da particularidade de cada turma, cabe ao professor decidir a melhor forma de conduzir a sistemática de análise do caso. Utilizar a estratégia do caso como nota avaliativa também pode ficar a critério do professor. 


\section{SUGESTÃO DE ANÁLISE DO CASO}

Nesse tópico, apresenta-se a análise das questóes sugeridas para discussão do caso, a fim de guiar o processo de ensino-aprendizagem. É oportuno reforçar que outras questóes podem ser elaboradas pelo professor, de acordo com o objetivo de aplicação do caso.

Questáo 1. Em razão do isolamento social ocasionado pela pandemia da COVID-19, a UFPB propôs implementar um calendário suplementar para ser executado de maneira remota. Como você analisa o processo de mudança organizacional requerido nesse contexto enfrentado pela UFPB?

O caso apresenta um cenário de mudança substancial ocasionada por um fator externo à organização (universidade). Nesse sentido, o professor deve direcionar os alunos para a compreensão da mudança em si, por meio de suas definiçóes teóricas dentro do contexto organizacional, bem como para a análise desse processo de mudança sob um ponto de vista amplo e sistêmico. Assim, o professor pode utilizar questóes elementares para introduzir a discussáo: Qual é a mudança tratada no texto? Qual o motivo dessa mudança? A recomendação é que o professor deixe a turma à vontade para definir e analisar o processo de mudança a partir de teorias que envolvam cultura e mudança organizacional vistas em aulas anteriores.

Especificamente, indica-se que o professor possa se basear em um dos modelos clássicos de mudança organizacional, fornecido por Kurt Lewin, no qual o processo de mudança ocorre em três etapas: Unfreezing (descongelar), Moving (mudar) e Refreezing (recongelar). O modelo enfatiza que a mudança eficaz perpassa pelo descongelamento da situação vigente, passando para uma condição desejada, para que depois ocorra um recongelamento. Assim, a primeira etapa se refere ao entendimento sobre a necessidade da mudança, para que o status quo seja quebrado. A segunda etapa envolve a mitigação dos fatores que geram a resistência à mudança. Já a etapa de descongelamento se relaciona às açóes para que a mudança seja duradoura (McShane \& Glinow, 2014).

Desse modo, o professor deve estimular que os alunos apresentem elementos que motivam a mudança do status quo (descongelamento), deixando claro qual o alvo da mudança e a necessidade de criar uma urgência para essa mudança, o que estimula o enfrentamento dos riscos associados a esse processo (McShane \& Glinow, 2014). Nesse momento, algumas evidências podem ser encontradas no texto, tais como: a pressão externa de outras instituiçóes (o próprio governo, por exemplo), a falta de referências no país sobre adotar o ensino remoto emergencial em IES pública, a necessidade de manter os alunos engajados e envolvidos com a universidade, a diminuição dos danos para a educação, dentre outros. Outros motivos podem surgir durante a discussão que não estejam explícitos no texto, mas que fazem parte do contexto vivenciado.

Em contrapartida, também se deve fazer com que os alunos identifiquem as forças restritivas que incentivam a manutençáo do status quo, criando uma resistência à mudança (McShane \& Glinow, 2014). É importante deixar claro que uma organizaçáo, em qualquer processo de mudança, busca manter a situaçáo vigente, tendendo a preservar a estabilidade (Dias, 2013). Nesse momento, o professor pode questionar: Por que há essa tendência de manter o status quo? O objetivo é evidenciar a importância de se compreender que a cultura organizacional é produto de um processo histórico, de experiências vividas e acumuladas e que, por isso, é formada por crenças, valores e comportamentos, que servem de referência para as decisóes acerca do processo de mudança. Por isso, a mudança significa modificar ou reinterpretar esses valores que estão integrados e que, muitas vezes, estáo operando no nível inconsciente (Dias, 2013).

No intuito de tornar a discussão mais concreta, o professor deve explorar os diversos aspectos envolvidos nas mudanças organizacionais, tanto com elementos do caso como com outros inerentes a qualquer processo de mudança. Alguns desses aspectos, baseados em Dias (2013) e que podem ser explorados pelo professor, são:

a. Toda mudança é essencialmente um processo político que envolve relaçóes de poder, principalmente em uma organização como uma instituição pública de ensino superior;

b. O processo de mudança requer a busca por um equilíbrio entre flexibilidade e rigidez, de acordo com a conjuntura do contexto;

c. A mudança rompe com rotinas estabilizadas, provocando medo devido às incertezas;

d. Mudanças trazem riscos que precisam ser considerados;

e. Processos de mudança requerem tempo para serem internalizados, compreendidos e absorvidos pelos atores da organização;

f. A importância de haver uma equipe de trabalho para guiar o processo de mudança;

g. O envolvimento das pessoas no processo é fundamental para gerar engajamento e apoio para a mudança;

h. Todo processo de mudança precisa ser planejado e organizado. 
Cabe, ainda, ponderar sobre o tamanho organizacional da UFPB, e a consequente pluralidade dos atores organizacionais, bem como a natureza dos seus processos, que são mais hierarquizados e burocráticos, o que torna a mudança consideravelmente mais desafiadora. Com isso, o professor pode ressaltar os aspectos que perpassaram a mudança no contexto vivenciado pela UFPB.

Questáo 2. Considere que toda mudança pressupóe resistência. No caso da implementação do calendário suplementar na UFPB, como você avalia as manifestaçóes de resistência da comunidade acadêmica? Quais açóes foram implementadas a partir do exposto no caso? Que outras açôes poderiam ter sido realizadas para superá-las?

Essa questão tem o intuito de levar os alunos a discutirem sobre a resistência como uma das principais barreiras à mudança organizacional. A partir dela, o professor pode explorar os conhecimentos prévios dos alunos sobre os processos de resistência à mudança, fazendo questóes introdutórias como: Quem já vivenciou algum processo de mudança organizacional? Conseguiu perceber se houve resistência durante a implementação do processo de mudança?

$\mathrm{Na}$ sequência, o professor pode se apoiar em Robbins (2015), a fim de ressaltar que, em geral, a resistência emerge no nível individual ou organizacional. No nível individual, as pessoas normalmente se opóem à mudança por questóes como hábitos, segurança e medo do desconhecido. Já as organizaçóes, por terem uma natureza conservadora, resistem ativamente à mudança por meio da inércia, que tanto pode ocorrer na estrutura quanto pode advir dos atores que serão impactados.

Assim, o professor pode destacar paralelos entre os conceitos apresentados a partir de Robbins (2015) e as respostas trazidas pelos alunos. $\mathrm{O}$ caso ajudará na discussão na medida em que o professor resgate os diálogos que expóem a resistência individual, especialmente quando são mencionadas preocupaçóes como aprender novas tecnologias, trabalhar com filhos em casa, náo ter as plataformas necessárias, ter maior esforço para preparar materiais em um novo modelo de ensino, etc. Já a ausência de adaptaçáo da estrutura do AVA vigente para um layout mais atrativo e a elevada evasão dos docentes nos cursos de capacitaçáo para as ferramentas do Moodle se configuram como exemplos de resistências organizacionais.

Nesse ponto, conhecendo o cenário da implementação da mudança, bem como as resistências advindas dele, o professor pode explorar a avaliaçáo dos alunos sobre as resistências apresentadas, fazendo questionamentos que os levem a pensar em estratégias de superação dessas resistências. Por exemplo: Como vocês avaliam as resistências individuais apresentadas no caso? E as resistências organizacionais? Conseguem pensar em açóes para superar essas resistências?

Nesse ponto, o professor pode explorar Ramos (2017), sob a perspectiva de que, para que qualquer processo de mudança possa ser pensado, é necessário que os gestores considerem estratégias de implementação, soluçooes alternativas e maneiras de superar as resistências à mudança, sobretudo iniciando uma discussáo sobre a necessidade da mudança, e levando os alunos a refletirem e reconhecerem o seu papel gerencial e de tomador de decisóes. A partir desse reconhecimento, o professor pode introduzir a discussão sobre a superação das resistências. Para tal, ele pode fazer uso da base conceitual apresentada por Daft (2008) e Ramos (2017).

Para mitigar resistências, Daft (2008) sugere algumas técnicas que podem ser usadas a fim de obter sucesso na implementação da mudança, como comunicação, participação no projeto da mudança, negociação por meio de barganha formal para ganhar aceitação e aprovação, coerção por meio do poder formal e apoio da alta direção. No caso, é possível identificar que diversas dessas açóes foram realizadas pela equipe da PRG, uma vez que as muitas reunióes que aconteceram durante o processo de tomada de decisão para a mudança não apenas buscaram comunicar a sua necessidade, mas também envolver, inicialmente, os assessores de graduação, negociando com eles um formato de calendário suplementar que obtivesse aprovação.

Adicionalmente, com base no diagnóstico elaborado pelo ODG, as evidências trazidas por meio dos dados permitiram, em alguma medida, reduzir a resistência daqueles que afirmavam que mais de $42 \%$ dos estudantes não tinham acesso ao ensino remoto devido ao seu perfil socioeconômico. Nesse sentido, a comunicação se torna uma ação estratégica importante, principalmente ao permitir que os tomadores de decisão explorem as informaçôes por filtros disponíveis.

Isso também converge com a proposição de Ramos (2017) acerca das estratégias para superaçáo das resistências, que são a educação e comunicação, o envolvimento dos empregados, a facilitaçáo e apoio da gestão de topo, a negociação, a cooperação e a coação. Dessas estratégias, é possível identificar as que poderiam ser melhor utilizadas pela PRG para ultrapassar as dificuldades e conseguir o comprometimento, especialmente dos professores.

Para além das açôes implementadas, outras podem ser sugeridas. No que diz respeito à educação e comunicação, o professor pode levar os alunos a refletirem sobre o processo de reunióes que ocorreu para a retomada do calendário e argumentar que as reunióes eram limitadas para grupos específicos, o que excluía a maior parte da comunidade 
acadêmica. Já sobre a facilitação e o apoio, ele pode reconhecer a necessidade de uma capacitação efetiva para que os professores fossem aptos para lidar com o medo e a ansiedade associados ao esforço de mudança, adquirindo novas competências ou capacidades. Todas essas estratégias podem ajudar na superação das resistências iniciais.

Questáo 3. Discuta o papel do Observatório de Dados da Graduação (ODG) para a tomada de decisão no processo de mudança organizacional da UFPB.

Nessa questão, o professor deve explorar a discussão sobre a relevância da comunicação como estratégia, e sobre a necessidade de obter informaçóes relevantes para a tomada de decisões em um processo de mudança organizacional. Essas informaçóes devem permitir um diagnóstico sobre a realidade da situação, servindo como um instrumento de discussão nos espaços relativos ao processo de mudança.

O caso apresentou os dados levantados pela PRG, por meio do ODG, em que mais de 14.000 estudantes responderam um questionário para identificar o perfil de acesso à internet e a tecnologias remotas. Para suscitar a discussão a partir desse fato, o professor deve questionar a importância dessa ação para o processo de mudança. Deve ficar claro que o diagnóstico dessa pesquisa permitiu esclarecer algumas crenças que vinham sendo colocadas como, por exemplo, o percentual de estudantes em situação de vulnerabilidade (renda familiar e escola de origem) que possui algum tipo de conectividade e acesso ao computador/ notebook. Além disso, o resultado apontou que pelo menos $3 / 4$ dos estudantes participariam do período suplementar.

O caso mostra que havia uma percepção equivocada sobre um dos aspectos da realidade, o que estava servindo como uma força restritiva ao processo de mudança, favorecendo aumento da resistência (Dias, 2013). Desse modo, o professor deve garantir que os alunos compreendam que o papel do ODG foi o de levantar dados que permitiram dar maior objetividade a alguns aspectos considerados sensíveis no processo de mudança organizacional, diminuindo as incertezas, o que gerou mais segurança aos tomadores de decisão e à comunidade acadêmica de forma geral.

Assim, as informaçóes, e os dados provenientes delas, devem ser de boa qualidade, permitindo que as conclusóes oriundas elevem, consequentemente, a qualidade das decisóes. Há um fato no texto que pode ser explorado, concernente à pesquisa realizada por um centro acadêmico estudantil, que revelou alguns dados que reforçavam a resistência à mudança. $\mathrm{O}$ professor deve usar esse exemplo para fomentar uma discussão sobre o uso de dados no debate que permeia o processo de mudança, questionando se os alunos identificaram problemas no levantamento realizado pelo centro acadêmico.
A resposta deve ir em direção ao meio utilizado Google Forms, que, para a coleta de dados, não garante a autenticidade dos respondentes (já que qualquer pessoa pode responder ao questionário), nem a unicidade das respostas (já que a mesma pessoa pode responder o questionário várias vezes). Além disso, os números percentuais precisam ser observados com cautela, pois podem, em alguma medida, confundir o tomador de decisáo. No exemplo do texto, 2,7\% dos estudantes moram em zona rural, o que representa oito estudantes que participaram da pesquisa. Destes, $50 \%$ não possuem computador, o que representa quatro estudantes; e $12,5 \%$ náo possui internet, o que representa um único estudante. É importante salientar que os dados para balizar a tomada de decisão, em organizaçóes como uma universidade, serão usados tanto para quem é a favor quanto para quem é contra o processo de mudança.

Desse modo, considerando que esses dados são relevantes para o processo de tomada de decisão, é indispensável a atenção ao planejamento metodológico, a fim de se alcançarem resultados confiáveis balizados em rigor científico, o que envolve preocupaçóes como: a qualidade do instrumento, o processo e estratégia de coleta, a representatividade da amostra, a análise dos dados e a comunicação da informação. Esse planejamento metodológico é ilustrado no caso, e o professor pode ressaltar esse processo - principalmente porque a divulgação de dados com problemas metodológicos pode representar dificuldades sobre a interpretaçáo da realidade e, portanto, dificultar a tomada de decisão e, consequentemente, o processo de mudança.

Questão 4. Ao se colocar na posição de Ariane, como próreitora de graduaçáo, qual seria a sua decisão, seguir ou recuar com o calendário suplementar? Apresente argumentos para justificar sua escolha.

O objetivo dessa questão é exercitar a capacidade de o aluno se posicionar diante de uma decisão crítica, bem como fazê-lo refletir sobre as justificativas e possíveis consequências dessa decisão. Desse modo, o aluno deve se colocar no lugar do gestor público e decidir sobre o dilema posto no caso. Para tanto, o professor deve incentivar a construção de alternativas para tomada de decisão, considerando que, mesmo havendo duas principais (prosseguir com o calendário suplementar ou esperar), o aluno poderá apresentar outras alternativas.

Com isso, o professor deve estar preparado para que a decisão, bem como suas respectivas justificativas, possa suscitar discussóes relevantes e expor pontos de vistas antagônicos. Nesse sentido, podem ser feitas questóes para os alunos, tais quais: $\mathrm{O}$ que os levou a apresentar essa alternativa como a melhor para a tomada de decisão? Quais as consequências dessa decisão para a organização e seus stakeholders? 
O posicionamento dos alunos poderá revelar, inclusive, diferentes perfis de enfrentamento sobre o problema, ou seja, aqueles alunos mais propensos a aceitar e aqueles mais resistentes a mudanças. Nesse momento, o professor pode convidar os alunos a refletirem sobre suas decisões, revelando como possíveis crenças, inclinações ou predileçoóes podem afetar as diferentes decisóes de sua vida pessoal e profissional.

\section{DESFECHO DO CASO}

O Consepe se reuniu nos dias 11, 14 e 18 de maio de 2020, aprovou a resolução que regulamenta provisoriamente o período suplementar e permitiu que atividades de ensino e aprendizagem remotas fossem realizadas para a graduaçáo, de 8 de junho a 14 de agosto de 2020. Portanto, a decisão tomada pela PRG foi de dar continuidade à proposta de um período suplementar com atividades remotas. Para tanto, várias ações foram realizadas:

a. Implementação, configuração e disponibilizaçáo de um novo AVA, denominado Moodle Classes, com uma aparência mais moderna, melhorando a usabilidade dos AVAs disponíveis até então pela instituição;

b. Realização de capacitaçóes para docentes e discentes para o uso do Moodle Classes, além da publicação de tutoriais e manuais;

\section{REFERÊNCIAS}

Daft, R. (2008). Organizaçóes: Teoria e projetos. (9a ed.). São Paulo: Cengage Learning.

Dias, R. (2013). Cultura organizacional: Construção, consolidação e mudanças. Sáo Paulo: Atlas.

McShane, S. L., \& Von Glinow, M. A. (2014). Comportamento Organizacional. (6a ed.). Porto Alegre: AMGH.

Ramos, M. M. A. (2017). Empreendedorismo, inovação e mudança organizacional. (v. 3). Coimbra: Actual Editora. c. Desenvolvimento de integraçóes entre o Moodle Classes e o sistema de gestão acadêmica da instituição (Sigaa), permitindo a inclusão automática dos estudantes matriculados no AVA;

d. Disponibilização de um portal de dúvidas, que funcionou como um canal central, para que a comunidade acadêmica pudesse registrar as suas dúvidas e obter respostas; além disso, foram criados canais de comunicação via WhatsApp para tornar a comunicação mais ágil;

e. Realização de reunióes nos centros de ensino para esclarecer a proposta, o que permitiu o envolvimento dos diferentes atores institucionais no processo de mudança;

f. Flexibilização das atividades docentes como, por exemplo, permitir que compartilhassem disciplinas e registrassem as capacitaçóes em suas cargas horárias.

As ofertas de turmas no período suplementar permitiram que mais de 18.000 estudantes se envolvessem em atividades de ensino remoto, o que corresponde a cerca de $76 \%$ do universo de estudantes quando considerada a média dos últimos períodos regulares. Ademais, a UFPB serviu de referência para outras IESs públicas, pelo caráter de vanguarda na capacidade de adaptação em tempos de crise como o da COVID-19. Após o início do período suplementar, a PRG iniciou o planejamento para um novo período remoto.
Robbins, S. P. (2015). Lidere e inspire: A verdade sobre a gestão de pessoas. São Paulo: Saraiva.

Universidade Federal da Paraíba (2019). Histórico. Retrieved from https://www.ufpb.br/ufpb/menu/institucional/ apresentacao/historico

Universidade Federal da Paraíba (2020). Pró-Reitoria de Graduação. Retrieved from http://www.prg.ufpb.br/ 


\section{Autoria}

\section{Diana Lucia Teixeira-de-Carvalho*}

Universidade Federal da Paraíba, Centro de Ciências Sociais Aplicadas, Departamento de Administração

Cidade Universitária, s/n, Castelo Branco, 58051-900, João Pessoa, PB, Brasil

E-mail: diana.carvalho@academico.ufpb.br

(D) https://orcid.org/0000-0001-6454-8604

\section{Jose Jorge Lima Dias Junior}

Universidade Federal da Paraíba, Centro de Ciências Sociais Aplicadas, Departamento de Administração

Cidade Universitária, s/n, Castelo Branco, 58051-900, João Pessoa, PB, Brasil

E-mail: jorge.dias@academico.ufpb.br

(D) https://orcid.org/0000-0003-4381-1930

\section{Ana Carolina Kruta-Bispo}

Universidade Federal da Paraíba, Centro de Ciências Sociais Aplicadas, Departamento de Administração

Cidade Universitária, s/n, Castelo Branco, 58051-900, João Pessoa, PB, Brasil

E-mail: ana.kruta@academico.ufpb.br

(D) https://orcid.org/0000-0002-0664-8575

* Autora Correspondente

\section{Financiamento}

Os autores relataram que não houve suporte financeiro para pesquisa deste artigo.

\section{Conflito de Interesses}

Os autores informaram que não há conflito de interesses.

\section{Verificação de Plágio}

A RAC mantém a prática de submeter todos os documentos aprovados para publicação à verificação de plágio, mediante o emprego de ferramentas específicas, e.g.: iThenticate.

\section{Contribuiç̧ões dos Autores}

$1^{\text {a }}$ autora: conceituação (igual); investigação (igual); administração de projeto (igual); supervisão (igual); escrita - rascunho original (igual); escrita - revisão e edição (igual).

2o autor: conceituação (igual); investigação (igual); administraçáo de projeto (igual); supervisão (igual); escrita - rascunho original (igual); escrita - revisão e edição (igual).

$3^{a}$ autora: conceituação (igual); investigação (igual); administração de projeto (igual); supervisão (igual); escrita rascunho original (igual); escrita - revisão e edição (igual).

\section{Direitos Autorais}

A RAC detém os direitos autorais deste conteúdo.

\section{Método de Revisão por Pares}

Este conteúdo foi avaliado utilizando o processo de revisão por pares duplo-cego (double-blind peer-review). A divulgação das informaçóes dos pareceristas constantes na primeira página é feita somente após a conclusão do processo avaliativo, e com o consentimento voluntário dos respectivos pareceristas.

\section{Disponibilidade dos Dados}

Todos os dados e materiais foram disponibilizados publicamente por meio da plataforma Harvard Dataverse e podem ser acessados em:

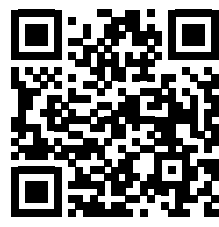

Diana Lucia Teixeira-de-Carvalho; Jose Jorge Lima Dias Junior; Ana Carolina Kruta de Araújo Bispo, 2021, "Replication Data for: Our calendar stopped! The organizational change at UFPB due to COVID-19", Harvard Dataverse, V1. https://doi.org/10.7910/DVN/EY3NJY

A RAC incentiva o compartilhamento de dados mas, por observância a ditames éticos, não demanda a divulgação de qualquer meio de identificação de sujeitos de pesquisa, preservando a privacidade dos sujeitos de pesquisa. A prática de open data é viabilizar a reproducibilidade de resultados, e assegurar a irrestrita transparência dos resultados da pesquisa publicada, sem que seja demandada a identidade de sujeitos de pesquisa. 